\title{
Changes in serum antibody titer following rabies vaccination in the giant panda
}

\author{
Liu SR ${ }^{1 *}$, Lan JC ${ }^{1}$, Luo L ${ }^{1}$, Ayala JE ${ }^{1}$, Hou R ${ }^{1}$, Feng $Y^{2}$, Liu L ${ }^{1}$, Liao L.H ${ }^{1}$, Huang WJ ${ }^{1}$, Xu WD ${ }^{2}$ and Guo \\ $\mathrm{HC}^{2}$
}

${ }^{1}$ Sichuan Key Laboratory of Conservation Biology for Endangered Wildlife, Chengdu Resetrch Base of Giant Panda Breeding, Chengdu 610081, Sichuan, People's Republic of China; ${ }^{2}$ Institute of Military Veterinary, Academy of Military Medical Sciences, Changchun 130122, Jilin, People's Republic of China

Article history

Received: 01 May, 2016

Revised: 20 May, 2016

Accepted: 23 May, 2016

\begin{abstract}
The aim of the present study was to assess the immune response and safety of a commercially available rabies virus vaccine in the giant panda. Serum antibody titers were measured and recorded during a one-year period post-vaccination. We injected 13 giant pandas with inactivated adjuvant vaccine against the rabies virus produced by NOBIVAC of Netherlands, followed by blood collection for serologic response. Rabies antibody titers were measured over a period of 12 months using the fluorescent antibody virus neutralization (FAVN) test. No adverse reactions were observed. Furthermore, the vaccine was able to elicit a strong immune reaction from recipients of adult groups, and maintain an adequate level of antibody titers for the duration of at least one year. Panda cubs received vaccines for the first time were $50 \%(2 / 4)$, developed an antibody response post-vaccination. We concluded that this vaccine is safe and effective for use in the giant panda, providing strong protection against exposure to rabies.

Keywords: Giant panda; rabies vaccine; antibody titer
\end{abstract}

To cite this article: Liu SR, Lan JC, Luo L, Ayala JE, Hou R, Feng Y, Liu L, Liao LH, Huang WJ, Xu WD and Guo HC, 2016. Changes in serum antibody titer following rabies vaccination in the giant panda. Res. Opin. Anim. Vet. Sci., 6(4): 121-125.

\section{Introduction}

Rabies is caused by neurotropic viruses of the genus Lyssavirus belong to the family Rhabdoviridae, and is transmissible to all mammals. Infections due to rabies have been described in numerous species of exotic felids, both in the wild and in captivity (Sillero et al., 1996; Rupprecht et al., 1998; Dennis et al., 1999; Haydon et al., 2002; Wack, 2003; Ellen et al., 2014; Aham et al., 2015). Serologic studies have also shown that rabies may pose a serious threat to wild and captive felid populations, like Namibian cheetahs (Munson et al., 2004), African lions (Packer et al., 1999), African wild dogs (Gascoyne et al., 1993; Vial et al., 2006) and laboratory dogs (Minke et al., 2009). Rabies is a zoonotic infectious disease of viral origin that causes distress of the central nervous system. Clinical signs in animals include erratic temperament and behaviour, irrational fever and anxiety, excess salivation, and pharyngetl muscle spasms. Death is caused by an

*Corresponding author: Liu SR, Sichuan Key Laboratory of Conservation Biology for Endangered Wildlife, Chengdu Resetrch Base of Giant Panda Breeding, Chengdu 610081, Sichuan, People's Republic of China; E-mail: srui_liu@163.com 
eventual paralysis of all functional organs and systems. Rabies is an epidemic with a high mortality of almost $100 \%$. As no clinical sign or gross post-mortem lesion can be considered pathognomonic in domestic or wild animals, the diagnosis of rabies has to rely on laboratory testing. Ahmad ea al. (2015) investigated the histopathological, immunohistochemical and molecular diagnosis of rabies in randomly selected ruminant's brain tissue found the rabies positive in goat and buffalo brain and suggested proper awareness, reliable prophylactic measures and diagnostic methods prevent the concurrent spread of the rabies virus in humans and animals. Surprisingly, the epidemiology of rabies has not been documented in the giant panda due to few reported cases; however, due to severity of disease once infected, protective measures such as vaccination should be taken for disease control and prevention.

Vaccinations against common infectious diseases such as rabies and canine distemper virus have been proven effective and have been widely used for many years. However, due to the scarcity of the giant panda population, there are a limited number of studies that document and report the changes in the serum antibody titer following exposure to vaccinations in this species. In addition, in and out of China, the used vaccines are different in their origin, country of production, quality, and other properties. Currently, there is no giant pandaspecific vaccination against the rabies virus. A number of zoos in China currently use an attenuated polyvalent canine rabies vaccine produced in China to vaccinate resident giant pandas. However, its effectiveness, the elicited antibody response, and the vaccination schedule have yet to be proven appropriate.

NOBIVAC ${ }^{\circledR}$ Rabies is a commercially available inactivated rabies vaccine for dogs and cats, and it is commonly used in zoos with other wildlife. NOBIVAC ${ }^{\circledR}$ Rabies was used in this study. We aim to assess the effectiveness of rabies vaccination in the giant panda by administering the vaccine and taking routine measurements of serum antibody levels. To our knowledge, no similar studies examining the changes in systemic antibody titers following rabies vaccination in the giant panda have been published in the veterinary literature. Our results will help us to understand the effectiveness of the rabies vaccine, as well as guide us to formulate an appropriate vaccination program for the giant panda.

\section{Materials and Methods}

\section{Vaccine and animals}

The vaccine used in this study is an inactivated adjuvant vaccine against rabies virus produced by Nobivac of Netherlands, which is for dogs and cats. This vaccine contains $\geq 2$ IU of the rabies virus strain RIV (Pasteur Institute) per vaccine dose. NOBIVAC ${ }^{\circledR}$
Rabies (Batch No: A158A01) was administered to all the giant pandas in this study.

All of the giant pandas were housed at the Chengdu Research Base of Giant Panda Breeding (CRBGPB). CRBGP classifies giant pandas by the following age groups as described by Zhang and Wei (2006): cubs (0.5-2 years); sub adults (2-4 years); adults (4-20 years); senior ( $>20$ years). For this study, only cubs and adults were used. The giant pandas were provisioned with bamboo, bamboo shoots, apples, panda bred like supplement produced at the CRBGPB. All the giant pandas in this study were presumed healthy and routine parasite control was administered monthly with $0.2 \mathrm{mg} / \mathrm{kg}$ give orally, Ivomec $^{\circledR}$ (MERIAL, INC, Waaederweg 39, Haarlem, Netherland). NOBIVAC ${ }^{\circledR}$ Rabies was given as a yearly vaccination via subcutaneous injection, one vial per dose.

\section{Blood collection}

Blood samples were collected from the basilica vein of the right or left arm using a $22 \mathrm{~mm}$-gauge needle and a vacuum blood collection tube. Pandas 1.5 years and up were trained to place their arms in a metal sleeve and allowed blood to be collected voluntarily for food rewards without anesthesia. Pandas which were younger than 1.5 years old were not yet trained, for this reason, blood was taken when they were restrained by keepers, from the basilica vein of the right or left arm. In this study, blood was collected prior to vaccine administration, one month, three months, six months, nine months, and one year post vaccination. The serum was separated by centrifugation at $1500 \mathrm{rpm}$ for $15 \mathrm{~min}$. The serum was labeled and stored in polypropylene tubes at $-80^{\circ} \mathrm{C}$ until later analysis.

\section{Serologic analyses}

Rabies antibodies titers were measured following administration of the rabies vaccine by fluorescent virus antibody neutralization (FAVN) (Cliquet et al., 1998) test which is recommended by the Office International Des Epizooties (OIE) as the highest standard. The minimum measurable antibody titer considered to represent a level of immunity in humans that correlates with the ability to protect against rabies infection is 0.5 IU per $\mathrm{mL}$ of rabies antibodies. Serum antibody level of these samples was measured by OIE Reference Laboratory for Rabies in China.

\section{Results}

Thirteen giant pandas were used for this study (four cubs, nine adults) and 78 samples of serum were obtained in total. In the months preceding the study, no pandas showed symptoms for any serious disease. Changes in serum antibody titer against rabies post 
Res. Opin. Anim. Vet. Sci., 2016, 6(4): 121-125.

Table 1: Changes in serum antibody titers against rabies post-vaccination

\begin{tabular}{|c|c|c|c|c|c|c|c|c|c|c|}
\hline \multirow[t]{2}{*}{ No. } & \multirow[t]{2}{*}{ Sex } & \multirow{2}{*}{$\begin{array}{l}\text { Age } \\
\text { (year) }\end{array}$} & \multirow[t]{2}{*}{ Group } & \multirow{2}{*}{$\begin{array}{c}\text { Titer pre-vaccination } \\
\text { (IU/ml) }\end{array}$} & \multicolumn{6}{|c|}{ Titer level at time (days) after vaccination (IU/ml) } \\
\hline & & & & & 14 day & 30 day & 90 day & 180 day & 270 day & 330 day \\
\hline 1 & $\mathrm{~F}$ & 20 & Adult & 1.50 & 3.42 & 3.42 & 5.92 & 1.97 & 1.5 & 0.87 \\
\hline 2 & $\mathrm{~F}$ & 6 & Adult & 0.50 & 1.14 & 7.79 & 1.92 & 0.87 & 1.14 & 0.29 \\
\hline 3 & M & 6 & Adult & 0.87 & - & 0.87 & 0.22 & 0.50 & 0.38 & 0.29 \\
\hline 4 & $\mathrm{~F}$ & 6 & Adult & 0.07 & - & 5.92 & - & 0.22 & 0.07 & 0.10 \\
\hline 5 & M & 6 & Adult & - & 1.97 & 0.87 & - & 0.29 & 0.22 & 0.22 \\
\hline 6 & $\mathrm{~F}$ & 8 & Adult & 0.50 & 7.79 & 5.92 & 1.14 & 1.97 & 0.87 & 0.50 \\
\hline 7 & M & 9 & Adult & 1.50 & 2.60 & 2.60 & 1.50 & 1.97 & 0.66 & 0.66 \\
\hline 8 & $\mathrm{~F}$ & 11 & Adult & 0.07 & 4.50 & 3.42 & 0.07 & - & 0.06 & 0.10 \\
\hline 9 & $\mathrm{M}$ & 13 & Adult & 0.50 & 0.87 & 0.87 & - & 0.38 & 0.29 & 0.29 \\
\hline 10 & M & 1 & Young & 0.01 & 0.66 & - & - & 0.10 & 0.06 & 0.17 \\
\hline 11 & $\mathrm{M}$ & 1 & Young & 0.17 & 0.22 & 0.38 & 0.22 & - & - & 0.17 \\
\hline 12 & $\mathrm{M}$ & 1 & Young & 0.02 & 0.22 & - & 0.10 & 0.17 & 0.10 & 0.10 \\
\hline 13 & M & 1 & Young & 0.03 & 0.50 & - & 0.50 & 0.10 & 0.13 & 0.06 \\
\hline
\end{tabular}

vaccination were shown in Table 1 . Rabies titers of 0.5 $\mathrm{U} / \mathrm{ml}$ or greater were considered protective. For the adults, $66.6 \%(6 / 9)$ of the pandas sampled had existing antibodies against the rabies virus even before vaccination at $\geq 0.5 \mathrm{IU} / \mathrm{ml}$, and the vaccine was able to stimulate a protective immune response in all the adult pandas (9/9). Only $50 \%$ of the cubs (2/4), developed an antibody response post-vaccination.

\section{Discussion}

Cubs that have not been previously exposed to the rabies vaccine showed an incomplete protective antibody titer against the rabies virus prior to the vaccination event $(<0.50 \mathrm{IU} / \mathrm{ml})$. Only $50 \%$ of them $(2 / 4)$, developed an antibody response post-vaccination, and both of them achieved a level of at least $0.50 \mathrm{IU} / \mathrm{ml}$ at two weeks postvaccination. However, due to unexpected circumstances, we were unable to collect whole blood from the cubs at the four-week mark to complete our data. As mentioned, the panda cubs were not yet trained for voluntary blood collection, for this reason, blood was taken when they were restrained, which was not always possible and led to several missed samples. Only half of the cubs mounted an appropriate antibody response with the peak antibody concentration occurring at two-weeks post-vaccination and decreasing thereafter. Even at the highest concentration their levels were barely above the threshold level required for adequate protection of $0.50 \mathrm{IU} / \mathrm{ml}$. When a panda first encounters a vaccine, it begins to mount an immune response for the first time toward the inoculated antigen. These antibodies produced tend to have a weak level of protection and short half-life. At the second vaccination event, the immune system is stimulated once more to the antigen, producing antibodies in higher concentrations and with longer half-lives. Thus, panda cubs that receive the vaccine for the first time cannot mount an adequate antibody response due to the young age as well as their immature immune system. As these pandas grow older their immune systems will begin to mature as well. A similar phenomenon was observed in cattle by Reis et al. (2009 \& 2013). These results suggest that an optimized vaccination plan be formulated or administer panda cubs with a booster dose of vaccine.

Of the adult pandas sampled, 66.6\% (6/9) had existing antibodies against the rabies virus even before vaccination at $\geq 0.5 \mathrm{IU} / \mathrm{ml}$, indicating that these pandas had most likely been previously vaccinated against rabies virus and the antibody has not yet dropped below detectable levels. It is reported that antirabies titer were detectable in horses at the initial sampling time (Muirhetd et al., 2008). In addition, on day 30, all of the adult pandas (9/9) presented an increase in antibodies with titers superior to the threshold of protection $(0.5 \mathrm{IU} / \mathrm{ml})$. Looking at the trend of the rise and fall in serum antibody concentrations, it can be speculated that the increase in antibodies is seen between two weeks and three months post-vaccination. From three months to nine months postvaccination antibody levels begin to decline, and by eleven months the serum antibody titer have returned to pre-vaccination levels or even lower. In a few pandas antibody titer provided protection against rabies at twelve months after vaccine exposure. This suggests that antibody titer in mature pandas are maintained in circulation for longer than those in immature ones and can provide protection for about one year. Therefore, for most giant pandas, vaccination against rabies virus can be conducted yearly to maintain protective levels of antibody titers in circulating serum at all times.

Louise et al. (2011) investigated factors associated with reaching the internationally accepted threshold antibody titre of $0.5 \mathrm{IU} / \mathrm{ml}$ following rabies vaccination in dogs. Two kinds of rabies vaccine were evaluated in their study and one is NOBIVAC ${ }^{\circledR}$ Rabies Vet which is the same vaccine used in our study. The results showed that dogs vaccinated at an age less than six months or over five years of age had a higher failure rate than dogs between six months and five years. This is in concordance 
with the findings of our study, the cubs had a higher failure than the adults. Mansfield et al. (2004) and Kennedy et al. (2007) also showed a higher risk of lower antibody titres with increasing age as well as for dogs less than one year of age compared to adults. Muirhead et al. (2008) evaluated the effect of age on the specific systemic antibody response after rabies and influenza vaccination in healthy horses, and the results showed that there was no significant difference in the antirabies neutralizing antibody titer response between the older and younger horses, the antirabies titer generated by both the younger and older horses were generally low. The older horses had a significantly reduced anamnestic response to influenza vaccine, this potentially could result in a reduced capacity of the elderly to respond to a novel pathogen compared with younger subjects (Cossarizza et al., 1997; Rocha et al., 1992; Ginaldi et al., 1999; Castle et al., 2000). In our study, there was no old age group so we do not know the effect of age on the antibody response, it is difficult to get blood samples continuously from the older giant pandas. Further studies should be conducted to elucidate the effectiveness of NOBIVAC ${ }^{\circledR}$ Rabies in the older giant pandas.

\section{Conclusions}

In the thirteen pandas that received the rabies vaccines produced by Nobivac, Netherlands, no adverse reactions to the vaccine were seen within one year postvaccination. The NOBIVAC ${ }^{\circledR}$ Rabies vaccine induced a serologic response in all of the pandas in our study from day 14 except for two cubs. The titers are considered protective, in accordance with the recommendations of the World Health Organization (titer $\geq 0.5 \mathrm{IU} / \mathrm{ml}$ ) (WHO, 2004). Antibody response is much more strongly elicited in adult pandas and maintained a protective level in circulation for a year. Therefore, we conclude that the vaccine is appropriate for use in giant pandas, and annual vaccination of giant pandas against the rabies virus using the killed vaccine produced by NOBIVAC is safe and recommended.

\section{Acknowledgements}

We are very grateful to all the staff in the department of animal husbandry in Chengdu Research Base of Giant Panda Breeding for their cooperation on the sample collection. We thank Dr. Wanxin Liu for her suggestions and her interest in this study. We declare no conflict of interest before submitting this manuscript to this journal.

\section{References}

Ahmad W, Mahmood F, Li Y, Duan M, Zhang M, Liu Z, Guan Z, Ali MA (2015) Abattoir based study of rabies virus in brain tissues of slaughtered animals using conventional diagnostic techniques. Res Opin Anim Vet Sci 5(12): 476-482.
Castle SC (2000) Clinical relevance of age-related immune dysfunction. Clin Infect Dis 31: 578-585.

Cliquet F, Aubert, MFA, Sagné L (1998) Development of a fluorescent antibody virus neutralizing test (FAVN test) for the quantitation of rabies-neutralising antibody. J Immunol Meth 212: 79-87.

Cossarizza A, Ortolani C, Monti D, Franceschi C (1997) Cytometric analysis of immunosenescence. Cytometry 27: 297-313.

Dennis LM, Cynthia AK, James FE and Todd KF (1999) Infectious disease and the conservation of freeranging large carnivores. Anim Conserv 2: 241-254.

Ellen B, Harry S, Cindy PD (2014) Serosurvey for selected pathogens in free-ranging American black betrs (Ursus americanus) in Maryland, USA. J Wildlife Dis 50(4): 829-836.

Gascoyne SC, Laurenson MK, Lelo S, and Borner M (1993) Rabies in African wild dogs (Lycaon pictus) in the Serengeti region, Tanzania. J Wildlife dis 29(3): 396-402.

Ginaldi L, De Martinis M, D’Ostilio A, et al. (1999) The immune system in the elderly: II. Specific cellular immunity. Immunol Res 20:109-115.

Haydon DT, Laurenson MK, Sillero ZC (2002) Integrating epidemiology into population viability analysis: managing the risk posed by rabies and canine distemper to the Ethiopian wolf. Cons Biol 16(5): 1372-1385.

Kennedy LJ, Lunt M, Barnes A, McElhinney L, Fooks AR, Baxter DN, Ollier WER (2007) Factors influencing the antibody response of dogs vaccinated against rabies. Vaccine 25: 8500-8507.

Louise TB, Ann-Kristin JN, Esteban R, Berndt (2011) Factors associated with the success of rabies vaccination of dogs in Sweden. Acta Vet Scand 53: 22.

Mansfield KL, Burr PD, Snodgrass DR, Sayers R, Fooks AR (2004) Factors affecting the serological response of dogs and cats to rabies vaccination. Vet Rec 154:423-426.

Minke JM, Bouvet J, Cliquet F, Wasniewski M, Guiot AL, et al. (2009) Comparison of antibody responses after vaccination with two inactivated rabies vaccines. Vet Microbiol 133(3): 283-286.

Muirhetd TL, McClure JT, Wichtel JJ, Stryhn H, Frederick RJ, McFarlane D, Lunn DP (2008) The Effect of Age on Serum Antibody Titers after Rabies and Influenza Vaccination in Healthy Horses. J Vet Intern Med 22:654-661.

Munson L, Marker L, Dubovi E, Spencer JA, Evermann JF et al. (2004) Serosurvey of viral infections in freeranging Namibian cheetahs (Acinonyx jubatus). J Wildl Dis 40: 23-31.

Packer C, Altizer S, Appel M, Brown E, Martenson J et al. (1999) Viruses of the Serengeti: patterns of infection and mortality in African lions. J Anim Ecol 68: 1161-1178. 
Reis LSLS, Chiacchio SB, Oba E, Pardo PE, FrazattiGallina NMV (2009) Association between handling stress in the corral and rabies antibody titers in selenium-supplemented cattle. J Venomous Animals and Toxins incl Trop Dis 15: 778- 788.

Reis LSLS, Pardo PE, Frazatti-Gallina NMV, Paoli RL, Oba E, Kronka SN, Camargos AS (2013) Effects of primovaccination and booster vaccination on serum cortisol and humoral immune response in cattle. Adv Biosci Biotechnol 4: 607-611.

Rocha B, Vassalli P, Guy-Grand D (1992) The extrathymic T-cell development pathway. Immunol Today 13:449-454.

Rupprecht CE, Stohr K, and Meredith C (1998) Infectious Disetses of Wild Mammals, 3rd edition. Manson Publishing, London, United Kingdom, p: 3-36.
Sillero ZC., King AA, and Macdonald DW (1996) Rabies and mortality in Ethiopian wolves (Canis Simensis). Journal of Wildlife Disetses 32: 80-86.

Vial F, Cletveland S, Rasmussen G, Haydon DT (2006) Development of vaccination strategies for the management of rabies in African wild dogs. Biological conservation 131: 180-192.

Wack RF (2003) Zoo \& Wild Animal Medicine, 5th edition. W B Saunders Co., Philadelphia, Pennsylvania, p: 491-500.

WHO Technical Report Series (2004) WHO Expert Consultation on Rabies, First Report. World Hetlth Organization, Geneva, Switzerland. 931: 121.

Zhang ZH and Wei FW (2006) Giant Panda ex-situ Conservation Theory and Practice. Science Press, Beijing, p: 65. 